\title{
IMMUNO- MORPHOLOGICAL PATTERNS OF LYMPH NODES DRAINING ORAL SQUAMOUS CELL CARCINOMA
}

\author{
Heba R. Mady ${ }^{*} B D S$, Zeinab Elsayed Darwish ${ }^{2} P h D$, Omneya R. Ramadan ${ }^{3} P h D$, \\ Amany M. Abdel-bary ${ }^{4} \mathrm{PhD}$
}

\begin{abstract}
INTRODUCTION: Head and neck cancer (HNC) is the sixth most common cancer with 500,000 cases diagnosed per year worldwide. Oral squamous cell carcinoma (OSCC) is accounting for more than $90 \%$ of total cases. Among all factors influencing the prognosis of OSCC, development of lymphatic metastasis is considered the single most important one. Morphological evaluation of the reactive patterns of regional nodes has aided in understanding the immune response to malignancy. The World Health Organization (WHO) categorized this reactive pattern into lymphocytic predominance, germinal center predominance, sinus histiocytosis, unstimulated pattern and lymphocytic depletion. Assessment of lymph nodes immuno- reactivity is an important indicator of the host response status and prognosis of OSCC.

OBJECTIVES: To Assess the immuno-morphological patterns of both positive and negative lymph nodes draining OSCC and correlate these patterns with the clinical finding and the histological grading of the primary tumor.

Material and Methods: Histopathological examination had been done on 30 cases of OSCC with neck dissection and immuno-morphological patterns had been detected and correlated with the grading of primary tumor.

Results: A statistical analysis of the distribution of the 5 patterns of lymph nodes in 3 grades of OSCC was done using chi square test. Significance difference was revealed only in two patterns (lymphocytic depletion and normal unstimulated patterns) .other 3 patterns was found to be non-significant.

CONCLUSIONS: lymphocytic depletion and unstimulated mixed patterns of draining lymph nodes was significantly correlated with the grade of the tumor and it could be used as an indicator for prognosis and early metastasis of OSCC. However, no correlation was found between the other patterns and the histological grading.

KEYWORDS: OSCC, immuno morphological patterns of lymph node.

RUNNING TITLE: Immuno morphological patterns correlated with the grading of OSCC.
\end{abstract}

1. Instructor in Oral Pathology Department, Faculty of Dentistry, Alexandria University.

2. Professor in Oral Pathology Department, Faculty of Dentistry, Alexandria University.

3. Lecturer in Oral Pathology Department, Faculty of Dentistry, Alexandria University.

4. Lecture in General Pathology Department, Faculty of Medicine, Alexandria university

*Corresponding author:

E-mail: heba.mady.2016@gmail.com

\section{INTRODUCTION}

Head and neck cancer (HNC) is the sixth most common cancer with 500,000 cases diagnosed per year worldwide (1). Oral squamous cell carcinoma (OSCC) is the most common head and neck cancer, accounting for more than $90 \%$ of total cases. The incidence of OSCC has increased over the past decades, as has its mortality (2).

There are various factors that influence prognosis of OSCC such as patient factors (age, sex and host immune response), tumor factors (size, site, histopathologic grade and metastasis) and treatment factors (chemotherapy and radiotherapy) (3). Among all these factors, development of lymphatic metastasis is considered the single most important factor influencing the outcome of the patient with OSCC, not only because it represents tumor aggressiveness but also because persistent tumor cells in The lymph nodes (LNs) can be a source of subsequent distant metastases to vital organs (4).

Fifty percent of patients with OSCC present nodal involvement that is detectable at the time of diagnosis. Of this group, less than $40 \%$ of the patients survive after five years compared to a $90 \%$ survival rate for patients without metastasis. Therefore, the existence of nodal metastasis decreases the survival rate by $50 \%(5,6)$.
With the remarkably rapid advances in modern immunobiology in the last decade, it has come to realization that there is a dynamic inter-relationship between the immunologic capacities of the lymphoid system and malignancy (7). In most of the immunologic studies, circulating blood lymphocytes were used as test cells. However, immune response may be recognized more clearly in structures close to the tumor, such as, in the proper tumor itself or in the draining LNs (8).

The World Health Organization (WHO) (1976) proposed a protocol for uniform assessment and reporting of lymph node reactivity patterns which were sub-categorized as lymphocytic predominance, germinal center predominance, sinus histiocytosis, unstimulated pattern and lymphocytic depletion (9).

Based on these criteria, several studies have been reported on the carcinomas of the cervix $(10,11)$, breast $(12)$ and larynx (13). However, few studies describing the lymph node immuno- reactive patterns of OSCC were reported (14-17)

The correlation between the lymph node immune response and other parameters such as site, size, and histopathological grade of the primary tumor is a reliable 
method to evaluate the host immune status, as well as an indicator of the potential of the cancer cells to invade (18).

\section{MATERIALS AND METHODS}

1)The present study was performed in the Faculty of Dentistry, Alexandria University after gaining the approval of the Research Ethics Committee. A retrospective study of thirty specimens diagnosed as oral squamous cell carcinoma that had undergone radical neck dissection or modified neck dissection in the archive of Oral Pathology Department of Faculty of Dentistry and General Pathology Department of Faculty of Medicine, Alexandria University were included in this study.

2) Sections had been taken from the paraffin blocks of the primary tumor and draining lymph nodes of fifteen cases proved histologically to have positive lymph node metastases and fifteen cases with negative LNs.

3) From the specimens' history, patients who presented any signs of active infection, autoimmune diseases, or having a history of radiotherapy, chemotherapy or other cancers were excluded from the study.

4) Serial sections of 3-4 $\mu \mathrm{m}$ thickness were placed on glass slides and stained using Hematoxylin and Eosin (H\&E).

\section{Statistical analysis}

Statistical analysis of the data

Data were fed to the computer and analyzed using IBM SPSS software package version 20.0. (Armonk, NY: IBM Corp). Qualitative data were described using number and percent. The Kolmogorov-Smirnov test was used to verify the normality of distribution. Quantitative data were described using range (minimum and maximum), mean, standard deviation and median. Significance of the obtained results was judged at the $5 \%$ level.

The used tests were

1. Chi-square test: For categorical variables, to compare between different groups.

2. Fisher's Exact or Monte Carlo correction: Correction for chi-square when more than $20 \%$ of the cells have counted less than 5

A (P) value less than 0.05 was considered significant. The values were given as a mean value \pm SD (standard deviation).

\section{RESULTS}

\section{Clinical Results}

The demographic data of the patients included in the current study are shown in Table 1 . In the present study, 30 patients with OSCC were included. The patient's age ranged between 29 and 75 years. Eighteen patients (60\%) were males and twelve patients (40\%) were females.

The most common site of occurrence was the lateral side of the tongue (53\%). The second common site of OSCC was the alveolar mucosa (27\%), followed by the cheek mucosa (14\%) finally, the floor of the mouth, and maxillary tuberosity were the least occurring site (3\%) for each.

Out of the 30 studied specimens, $83 \%(n=25)$ were ulcerative lesions, while $17 \%(n=5)$ were presented as exophytic forming fungating masses.

\section{Histopathological Results}

The microscopical examination revealed that $47 \%(n=14)$ of the cases were moderately differentiated. $30 \%(n=9)$ of cases were well differentiated OSCC and 23\% $(n=7)$ poorly differentiated squamous cell carcinoma were detected.

\section{Results of immuno-morphological patterns of lymph nodes}

In the present study, 224 lymph nodes were obtained from 30 specimens of OSCC. The most common pattern was lymphocytic predominance pattern 39.3\% (n=88) (Figure.1) followed by sinus histiocytosis pattern 23.3\% $(\mathrm{n}=52)$ (Figure.2) then germinal center predominance 18.3\% (n=41) (Figure.3), unstimulated pattern 10.7\% $(n=24)$ (Figure.4) and lymphocytic depletion 8\% $(n=19)$ (Figure.5).

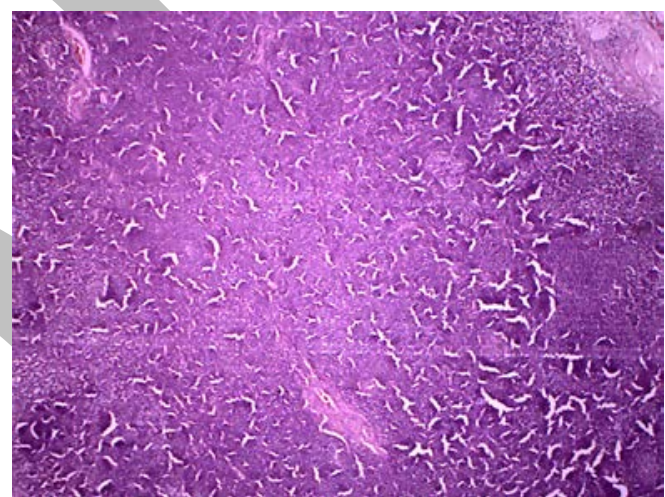

Figure (1): lymph node draining OSCC Revealing lymphocytic predominance pattern. (H\&E stain $\mathrm{x} 40$ ).

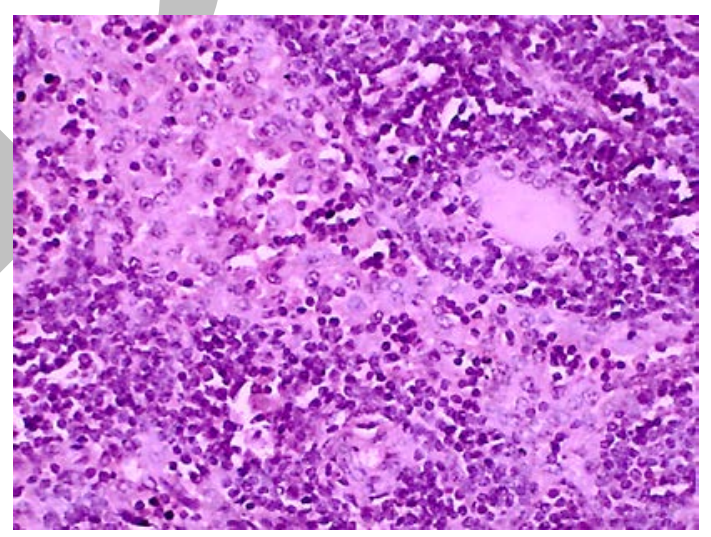

Figure (2): lymph node draining OSCC Revealing Sinus histiocytosis predominance pattern, Rash of. Histiocytes are evident (H\&E stain $\mathrm{x} 400)$.

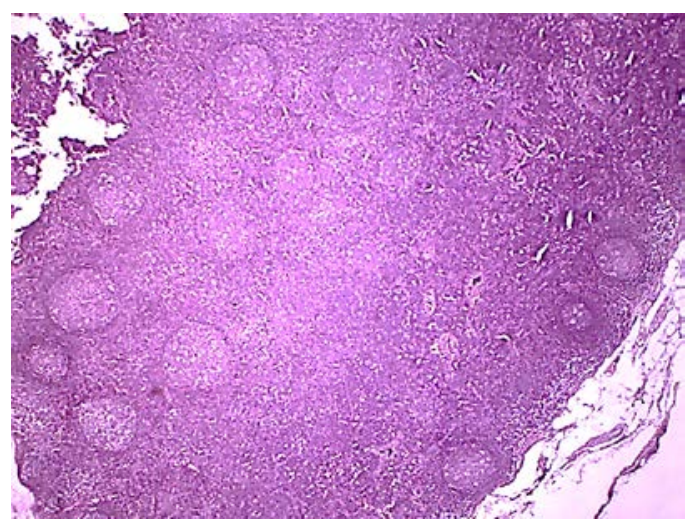


Figure (3): lymph node draining OSCC Revealing Germinal centers predominance pattern. (H\&E stain $\mathrm{x} 40$ ).

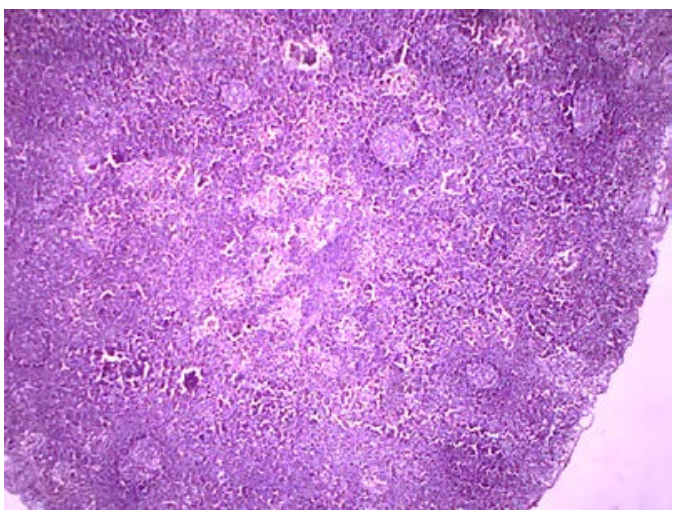

Figure (4): lymph node draining OSCC Revealing un stimulated pattern with equal distribution of germinal centers, lymphoid follicles and sinuses (H\&Ex40).

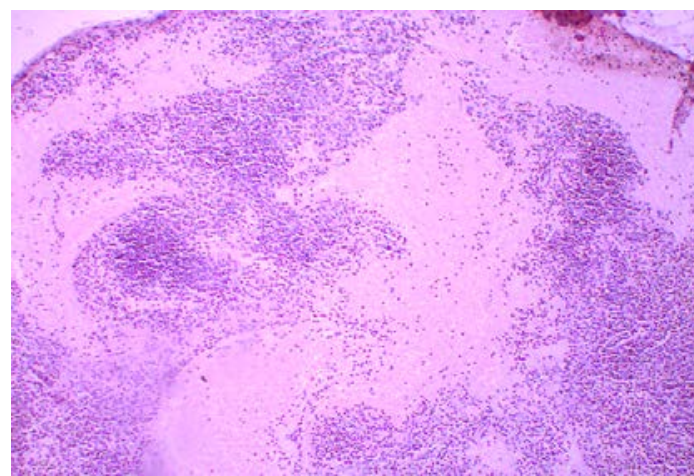

Figure 5: lymph node draining OSCC Revealing lymphocytic depletion pattern with hyalinization (H\&Ex100).

\section{Correlation between immuno-morphological patterns with grading of the tumors}

The total number of lymph node harvested from 9 cases of well differentiated squamous cell carcinoma was 61 L.Ns from which $43.4 \%(n=27)$ had lymphocytic predominance pattern, 18\% ( $\mathrm{n}=11)$ had germinal center predominance pattern, 19.7\% $(\mathrm{n}=12)$ had sinus histiocytosis pattern, $4.9 \%$ $(\mathrm{n}=3)$ had lymphocytic depletion pattern and 13.1\% $(\mathrm{n}=8)$ had unstimulated mixed pattern.

The total number of lymph node harvested from 14 cases of Moderately differentiated squamous cell carcinoma was 107 L.Ns from which $41.1 \%(n=44)$ had lymphocytic predominance pattern, $17.8 \%(\mathrm{n}=19)$ had germinal center predominance pattern, $23.4 \% \quad(\mathrm{n}=25)$ had sinus histiocytosis pattern, $3.7 \% \quad(n=4)$ had lymphocytic depletion pattern and $14 \%(n=15)$ had unstimulated mixed pattern.

The total number of lymph node harvested from 7 cases of Poorly differentiated squamous cell carcinoma was 56 L.Ns from which $30.4 \% \quad(n=17)$ had lymphocytic predominance pattern, $19.6 \%(\mathrm{n}=11)$ had germinal center predominance pattern, 26.8\% $\quad(\mathrm{n}=15)$ had sinus histiocytosis pattern, $21.4 \% \quad(\mathrm{n}=12)$ had lymphocytic depletion pattern and $1.8 \%(\mathrm{n}=1)$ had unstimulated mixed pattern.
A statistical analysis of the distribution of the 5 patterns of lymph nodes in 3 grades of OSCC was done using chi square test. Significance difference between the 3 groups was revealed only in two patterns (lymphocytic depletion and normal unstimulated patterns) $(\mathrm{P}<0.05)$. (Table.2) \& (Graph.1).

Table (1): Distribution of the Studied Cases according to Demographic Data

\begin{tabular}{||l|l|l||}
\hline & (n=30) & \% \\
\hline Age & \multicolumn{2}{|l||}{} \\
\hline$\leq 60$ & 20 & 67 \\
\hline$>60$ & 10 & 33 \\
\hline Min. - Max. & $29-75$ \\
\hline Mean \pm SD. & $60 \pm 10.5$ \\
\hline Median & 57 \\
\hline Gender & \multicolumn{2}{|||}{} \\
\hline Male & 18 & 60 \\
\hline Female & 12 & 40 \\
\hline & \multicolumn{2}{|l||}{} \\
$\begin{array}{l}\text { Clinical Variants } \\
\begin{array}{l}\text { Ulcerative } \\
\text { Exophytic }\end{array}\end{array}$ & 25 & 83 \\
& 5 & 17 \\
\hline $\begin{array}{l}\text { Lymph node metastasis } \\
\text { Positive } \\
\text { Negative }\end{array}$ & 15 & 50 \\
\hline
\end{tabular}

Table (2): correlation between immuno-morphological patterns of lymph nodes and grading of the tumors.

\begin{tabular}{|c|c|c|c|c|c|c|c|c|}
\hline & \multicolumn{6}{|c|}{ Grading } & \multirow{3}{*}{$\chi^{2}$} & \multirow{3}{*}{$\mathbf{p}$} \\
\hline & \multicolumn{2}{|c|}{$\begin{array}{c}\text { Poor } \\
(\mathrm{n}=56)\end{array}$} & \multicolumn{2}{|c|}{$\begin{array}{c}\text { Moderate } \\
(\mathrm{n}=107)\end{array}$} & \multicolumn{2}{|c|}{$\begin{array}{c}\text { Well } \\
(\mathbf{n}=61)\end{array}$} & & \\
\hline & No. & $\%$ & No. & $\%$ & No. & $\%$ & & \\
\hline LP & 17 & 30.4 & 44 & 41.1 & 27 & 44.3 & 2.656 & 0.265 \\
\hline GP & 11 & 19.6 & 19 & 17.8 & 11 & 18.0 & 0.092 & 0.955 \\
\hline SH & 15 & 26.8 & 25 & 23.4 & 12 & 19.7 & 0.831 & 0.660 \\
\hline LD & 12 & 21.4 & 4 & 3.7 & 3 & 4.9 & $16.12 *$ & $\begin{array}{c}<0.001 \\
*\end{array}$ \\
\hline $\begin{array}{l}\text { Sig. } \\
\text { bet. } \\
\text { grps }\end{array}$ & \multicolumn{6}{|c|}{$\mathrm{p} 1<0.001^{*}, \mathrm{p} 2=0.008^{*}, \mathrm{p} 3=0.705$} & & \\
\hline NOR & 1 & 1.8 & 15 & 14.0 & 8 & 13.1 & $6.255^{*}$ & $0.044^{*}$ \\
\hline $\begin{array}{l}\text { Sig. } \\
\text { bet. } \\
\text { grps }\end{array}$ & \multicolumn{6}{|c|}{$\mathrm{p} 1=0.013^{*}, \mathrm{p} 2=0.033^{*}, \mathrm{p} 3=0.870$} & & \\
\hline
\end{tabular}

2: Chi square test

MC: Monte Carlo

$\mathrm{p}$ : $\mathrm{p}$ value for comparing between the three 2groups

*: Statistically significant at $\mathrm{p} \leq 0.05$ 
Graph. (1): correlation between immuno-morphological patterns of lymph nodes and grading of the tumors.

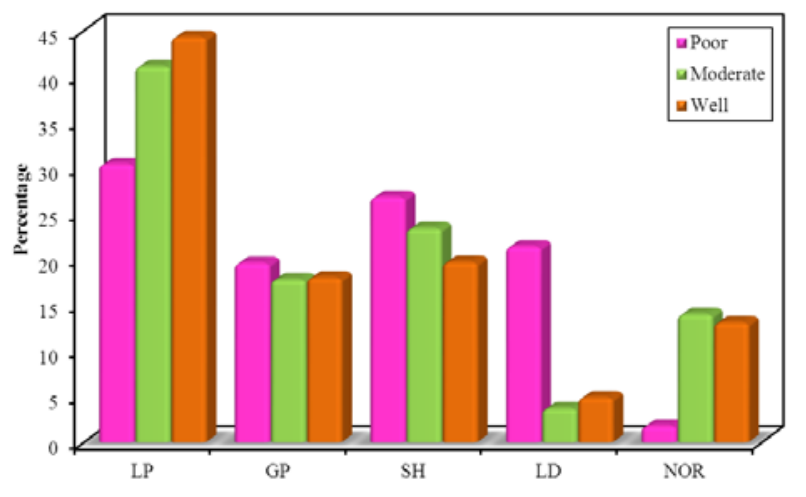

\section{DISCUSSION}

Squamous cell carcinoma comprises approximately 90\% of the cancers of the oral cavity. Despite optimal treatment, the prognosis of advanced SCC remains poor. This is primarily due to high rate of loco-regional failure and secondarily due to distant metastasis. Incidence of lymph node metastasis in head and neck cancer is high and is the most important prognostic factor. The incidence of neck metastasis in OSCC is relatively high (19).

The role of the host defense mechanism against tumor growth is gaining increased attention in clinical as well as experimental studies. Regional lymph nodes are considered to have their primary function not merely in the anatomic barriers to the systematic dissemination of tumor cells, but also in the immunological surveillance (20).

This study included lymph nodes from thirty specimens diagnosed as OSCC. Five histologic patterns were seen out of 224 harvested lymph nodes: Lymphocytic predominance, germinal center predominance, Sinus histiocytosis, lymphocytic depletion and unstimulated pattern.

Lymphocytic predominant pattern (L.P) was the most constant finding in lymph nodes, which was similar to previous studies in melanoma and colon cancer respectively $(21,22)$.

It is suggested that this pattern may be actively engaged in a cell-mediated immune response. It is also suggested that sinus histiocytosis and lymphoid hyperplasia are manifestations of cellular immunity and thus may indicate a favorable prognosis $(21,22)$.

Sinus histiocytosis (S.H) was the second common patterns in this study. Similar results were obtained by Okura et al (14), Nithya C (23), in OSCC and Tsakraklides et al. (24), in uterine cervical carcinoma. In sinus histiocytosis, a predominance of macrophages and histiocytes are not specific to any type of immune response. Accumulation of macrophages in sinus histiocytosis was directed toward the tumor and was believed to be the first morphological response of the host immune system against the tumor (14). However, Nagata et al. (25) in an experimental study of reactivity patterns in carcinoma induced in rats showed that follicular hyperplasia and lymphocyte proliferation were induced earlier than sinus histiocytosis in response to carcinoma.
This evidence that S.H develops only during the late stages of tumor growth in experimental animals, supports the fact that the presence of $\mathrm{SH}$ indicates more advanced stage of carcinoma thus correlating with the poorer patient prognosis.

Although germinal center predominance pattern (G.P) was the third common pattern, it was the second most common pattern associated with metastasis in this study. The same results were observed by Di Giorgio. (26) He hypothesized that, "cellular immune activity may prevent lymph node invasion, whereas, humoral response may facilitate metastases by blocking action of cellular immunity" in patients with lung carcinoma. This hypothesis was supported by other studies by Tosi.et al (27) in bronchogenic carcinoma and Hunter et al. (28) in mammary carcinoma.

In contrast Ioachim $\mathrm{H}$ et al (29) in their study on patients with head and neck carcinoma found that both germinal cell predominance and lymphocytic predominant pattern experienced less incidence of metastases, 23 and $31 \%$, respectively.

The second least common pattern in this study was unstimulated pattern. The same results were obtained by Chandavarkar V et al (30), he explains the question of how the tumor was present without immunological changes in the regional lymph nodes draining it, one possibility is that the tumor is only very weakly antigenic to stimulate the draining regional nodes. The other explanation was that distant level of lymph nodes lowering the chance for immunologic response in it.

Although the lymphocytic depletion pattern was the least common in this study, it was the most common pattern associated with metastasis. This pattern was always described in many studies as a pattern associated with exhausting immune response, metastases and bad prognosis. (31-33)

There was a statistically significant association between lymph node reactive patterns and histopathological grades of the tumor $(P<0.05)$. Higher numbers of unstimulated pattern of lymph nodes are found in Well and Moderate grades compared to poor one. On the other hand, higher number of lymphocytic depletion pattern were found in poorly differentiated pattern compared to other grades of tumor. Lymphocytic and germinal predominance patterns were higher in well and moderate grades compared with poorly differentiated one but with no significance.

Chandavarkar V et al (30) found that there was a statistically significant association between lymph node reactive pattern and histopathological grades of the tumor $(P<0.05)$ higher numbers of lymphocytic and germinal center predominance patterns of lymph nodes are found in well and moderate grades of OSCC. On the other hand, Raj L.S et al (34) found that lymphocytic depletion pattern was statistically significant $(p<0.05)$ with the worst grades of tumor and have unfavorable prognosis.

Since most of our patients were lost to be followed-up, our study could not include the prognosis of these patients. We believe that the node related parameters should be assessed for each OSCC patient and according to the 
findings, the patients should be categorized into the relevant risk categories. This will help the pathologist sending the referring surgeon a more informative report for assessing patient prognosis for formulating a more comprehensive treatment protocol. Further studies with larger sample sizes have to be done on lymph node related pathologic parameters to assess their prognostic significance.

\section{CONCLUSIONS}

Lymphocytic depletion and unstimulated mixed patterns of draining lymph nodes were significantly correlated with the histological grading of the tumor and it could be used as an indicator for prognosis and early metastasis of OSCC. But no correlation was found between the other patterns and the histological grading.

\section{CONFLICT OF INTEREST}

The authors declare that they have no conflicts of interest.

\section{REFERENCES}

1. Siegel R, Ma J, Zou Z, Jemal A Cancer statistics, 2014. CA Cancer J Clin .2014; 64:9-29.

2. Arduino PG, Carrozzo M, Chiecchio A, Broccoletti R, Tirone F, Borra E, et al. Clinical and histopathological independent prognostic factors in oral squamous cell carcinoma: A retrospective study of 334 cases. J Oral Maxillofac Surg. 2008; 66:1570-9.

3. Scully C, Bagan J. Oral squamous cell carcinoma overview. Oral Oncol J .2009;45:301-8.

4. SinemK, Michael D Mechanisms of lymphatic metastasis. J Clin Invest.2014; 124:922-928.

5. Sano D, Myers JN. Metastasis of squamous cell carcinoma of the oral tongue. Cancer Metastasis Rev 2007; 26: 64562.

6. Grimm M. Prognostic value of clinicopathological parameters and outcome in 484 patients with oral squamous cell carcinoma: Microva-scularinvasion $(\mathrm{V}+$ ) is an independent prognostic factor for OSCC. ClinTranslOncol 2012; 14: 870-80.

7. Woolgar JA. Histopathological prognosticators in oral and oropharyngeal squamous cell carcinoma. Oral Oncol 2006; 42:229-39.

8. Yadav ST, MadhuShankari G S, Chatura K, Dhanuja RJ, Rashmi M. Immunomorphological assessment of regional lymph nodes for predicting metastases in oral squamous cell carcinoma. Indian J Dent Res 2012; 23:121-2.

9. Hubert Low TH, Gao K, Elliott M, Clark JR. Tumor classification for early oral cancer: reevaluate the current TNM classification. Head Neck. 2015; 37:223-8.

10. Paladini D, Cross P, Lopes A, Monaghan JM. Prognostic significance of lymph node variables in squamous cell carcinoma of the vulva .Cancer. 1994; 74:2491-5.

11. Hegde V, Mumtaz WR, Khan S, Chandra P. KR 2017. “. Immunological status of metastatic and non metastatic lymph nodes in cervix carcinoma”, International Journal of Current Research.; 9:61551-5.

12. Silverberg SG, Chitale AR, Hind AD, Frazier AB, Levitt $\mathrm{SH}$. Sinus histiocytosis and mammary carcinoma. Study of 366 radical mastectomies and an historical review. Cancer.
1973; 26:1177-85.

13. Patt BS, Close LG, Vuitch F. Prognostic significance of sinus histiocytosis in metastatic laryngealcancer. Laryngoscope. 1993; 103:498-502.

14. Okura M, Kagamicuhi H, Tominanga G, Iida S, Fukuda Y, Kogo M. Morphological changes of regional lymph node in squamous cell carcinoma of the oral cavity. J Oral Pathol Med. 2005; 34:214-9.

15. VidyadeviCh, K Uma, R Sangeetha, and Mithilesh Mishra. Immuno morphological patterns of cervical lymph nodes in oral squamous cell carcinoma.J Oral MaxillofacPathol. 2014; 18: 349-355.

16. OKURA M, HIRANUMA T, KAGAMIUCHI H, SAWAI N, IIDA S, ISHII S, AIKAWA T, KOGO M. Long-term prognostic factors in squamous cell carcinoma of the oral cavity with a specific focus on lymph node metastasis. Journal of the Japanese Stomatological Society. 2010 Mar 10; 59(2):68-78.

17. Suchitra G, Puranik R, Vanaki S, Prasad BG, Malgaonkar NI. Immuno-reactivity of excised lymph nodes in neck dissections of squamous cell carcinomas of oral cavity. Journal of oral and maxillofacial pathology: JOMFP. 2015; 19: 128.

18. Cottier H, Turk J, Sobin L. A proposal for a standardized system of reporting human lymph node morphology in relation to immunological function. Bull WHO.1972; 47: 375-417.

19. Wermker K, Belok F, Schipmann S, Klein M, Schulze HJ, Hallermann C. Prediction model for lymph node metastasis and recommendations for elective neck dissection in lip cancer. JCraniomaxillofac Surg. 2015; 43(4):545-52.

20. Contaldo M, Di Napoli A, Pannone G, Franco R, Ionna F, Feola A,et al. Prognostic implications of node metastatic featuresin OSCC: a retrospective study on 121neck dissections. Oncol Rep. 2013;30(6):2697-704.

21. Lana AM, Wen DR, Cochran AJ. The morphology, immunophenotype and distribution of paracortical dendritic leucocytes in lymph nodes regional to cutaneous melanoma. Melanoma research. 2001 Aug 1; 11(4):40110.

22. Saldanha P, Nuzhath T. Significance of Immune Response Patterns in Lymph Nodes Draining Breast Carcinoma. International Journal of Innovative Research in Medical Science. 2017 Nov 25; 2(11):1468-to.

23. Tsakraklides V, Anastassiades OT, Kersey JH Prognostic significance of regional lymph node histology in uterine cervical cancer. Cancer. 1973; 31:860-8.

24. Nagata H, Arai $T$, Soejima Y. Limited capability of regional lymph nodes to eradicate metastatic cancer cells. Cancer. 2004; 64:8239-48.

25. Nithya C, Pandey M, Naik B, Ahamed IM. Patterns of cervical metastasis from carcinoma of the oral tongue. World J Surg Oncol 2003; 1:10.

26. Di Giorgio A, Mingazzini P, Sammartino P, Canavese A, Arnone P, Scarpini M. Host defense and survival in patients with Lung carcinoma. Cancer 2000; 89:2038-45. 
27. Tosi P, Luzi P, Leoncini L, Miracco C, Gambacorta M, Gross A. Brochogenic carcinoma: Survival after surgical treatment according to stage, histologic type and immunomorphologic changes in regional lymph nodes. Cancer 1981;48:2288-95

28. Hunter RL, Ferguson DJ, Coppleson LW. Survival with mammary cancer related to the interaction of germinal center hyperplasia and sinus Histiocytosis in axillary and internal mammary lymph nodes. Cancer 1975;36:528.

29. Ioachim HL, Medeiros LJ. Reactive Lymphoid Hyperplasia. In: Ioachim's Lymph Node Pathology 4thed. Philadelphia, Wolters Kluwer/Lippincott Williams and Wilkins 2009; p171-80.

30. Chandavarkar V, Uma K, Sangeetha R, Mishra M.J Prognostic Significance of Lymph Node Pattern in Oral Squamous Cell Carcinoma (OSCC). Oral Maxillofac Pathol. 2014 Sep-Dec; 18(3):349-55.

31. Khetarpal S, Mathur S K, Sethi D, Sen R. Immune hyperplasia patterns in lymph nodes draining breast cancer: A correlation with histomorphological parameters. Clin Cancer Investig J 2013;2:330-8.

32. Pihl E, Nairn RC, Milne BJ, Cuthbertson AM, Hughes ESR, Alex Rollo AJ. Lymphoid Hyperplasia.A Major Prognostic Feature in 519 Cases of Colorectal Carcinoma. Am J Pathol 1980, 100:469-80.

33. Koh DM, Brown G, Husband JE. Nodal staging in rectal cancer. Abdominal imaging. 2006 Dec 1;31(6):652-9.

34. Raj L.S., M., Boaz, K., \& Natarajan, S. (2014). Prognostic Significance of Lymph Node Pattern in Oral Squamous Cell Carcinoma (OSCC). Journal of Clinical and Diagnostic Research: JCDR, 8(1), 232-235. http://doi.org/10.7860/JCDR/2014/7365.3974.

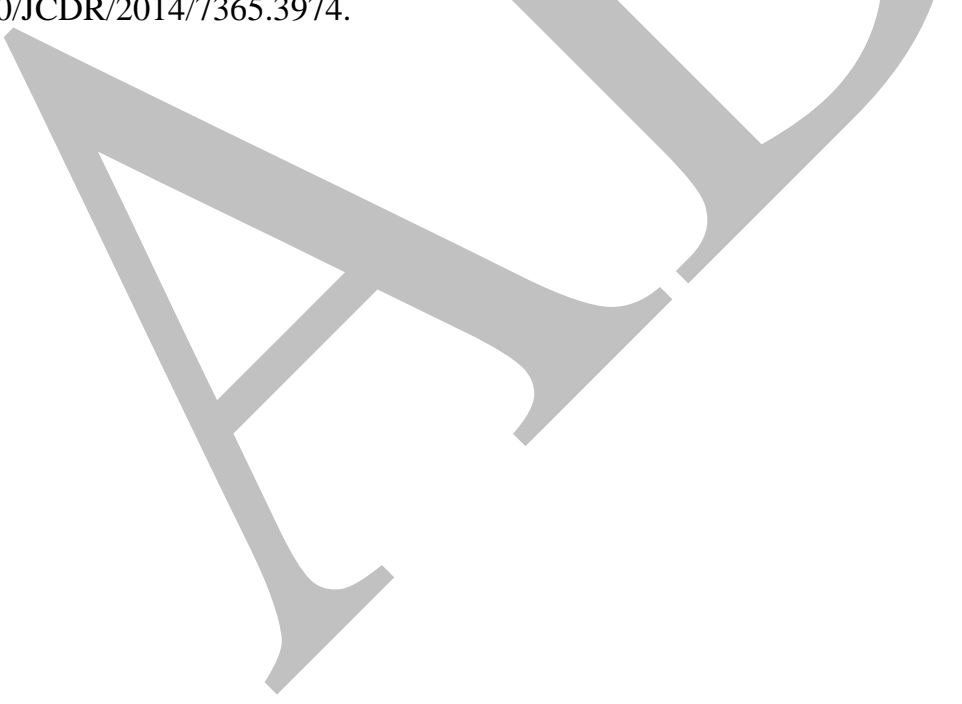

